\title{
Inappropriate Use of Risk Assessment in Addressing Health Hazards Posed by Civil Aircraft Cabin Air
}

\author{
Howard CV* \\ Centre for Molecular Biosciences, University of Ulster, UK
}

Submission: February 12, 2020; Published: December 04, 2020

*Corresponding author: Howard CV, Centre for Molecular Biosciences, University of Ulster, UK

Abstract

Toxicological reviews of data on Aerotoxic Syndrome that have been widely referenced by the airline industry tend to use a toxicological endpoint, Organo-Phosphate Induced Neuropathy (OPIDN), that is acknowledged to be the result of a very high dose of organophosphate exposure. Additionally, the reviews tend to only address one chemical, Tri-Ortho Cresyl Phosphate (TOCP), ignoring the presence of other toxic compounds in a complex mixture. In using this to justify the safety of the continued use of unfiltered engine bleed air to ventilate civil aircraft cabins, this represents a misuse of toxicological risk assessment. The approach totally ignores the scientific literature on repeated low-dose exposure to OPs over extended periods, the constant presence of a complex mixture of OPs in engine bleed air and their overall toxicity and the variable susceptibility of individuals to toxicological damage. This paper lists the above-mentioned studies and reviews a sub-set. We present the scientific literature that should be considered to make a realistic risk assessment of the hazards of aircraft engine bleed air.

Keywords: Aerotoxic syndrome; Jet engine bleed air; Organophosphate toxicity; Cresyl phosphate; Neurological symptoms; Comparative toxicology

Abbreviations: TCP: Tricresyl Phosphate; Ops: Organophosphates; TAPs: Triaryl Phosphates; TOCP: Tri-Ortho Cresyl Phosphate; OPIDN: Organophosphate Induced Neuropathy; OCP: Ortho-Cresyl Phosphate; NTE: Neuropathy Target Esterase; UF: Uncertainty Factor

\section{Background}

Lubrication oils in gas turbine aero engines require the presence of synthetic lubricants, which include additives, to minimize engine wear at the high temperatures encountered in normal operation [1-3]withstand high specific loadings and extreme environmental conditions within short times. Requirements are critical. Piston engines increasingly use multigrade oils, single grades are still used extensively, with anti-wear and anti-corrosion additives for some classes of engines. The main gas turbine lubricant problem is transient heat exposure, the main base oils used are synthetic polyol esters which minimise thermal degradation. Aminic anti-oxidants are used together with antiwear/load-carrying, corrosion inhibitor and anti-foam additives. The majority of formulation viscosities are $5 \mathrm{cSt}$ at $100^{\circ} \mathrm{C}$. Other considerations are seal compatibility and coking tendency. Aviation hydraulic fluids are divided into military, mainly PAO based, and civil aircraft which are mainly phosphate ester based. The first contains anti-oxidant, anti-wear and seal compatibility additives, the second prefers trialkyl over triaryl phosphates and contains anti-hydrolysis additives. Aviation greases are subject to extreme operating conditions, such as high-temperature conditions up to $550^{\circ} \mathrm{C}$ in wheel bearings and resisting water ingress. Airframe and wheel bearing greases are of two types, either lithium soap/ complex or clay based. Helicopter transmission lubricants serve the most critical gears in aviation, carrying power for both thrust and lift. Ester-based lubricants are either the same grade as the engine, or a different engine lubricant grade, or a grade intended specifically for helicopter transmissions. (C) 2010 Springer Science+Business Media B.V.",' author":[\{“dropping-particle":"',',fa mily":"Lansdown",'given":"A. R.,"'non-dropping-particle":"',"'parsenames":false,"suffix":"'\},\{“dropping-particle":"',',family":"Lee","g iven":"S.,",non-dropping-particle":"',",parse-names":false,"suffix" :"'”\}],"container-title":"Chemistry and Technology of Lubricants: Third Edition",'id":"ITEM-1",'issued":\{“date-parts":[[“2010”]] \},"title":"Aviation lubricants",'type":"chapter"\},"uris":[“http:// www.mendeley.com/documents / ? u uid=f33389 c 2 918 e - 3 cd 8- 845 c- 516 d 578 b 4788 "] \}, \{ “id": "I T E M 2","itemData":\{“DOI":"10.5772/intechopen.82398","author ":[\{“dropping-particle":"”,",family":"Johnson","given":" David 
","non-dropping-particle":",,"parse-names":false,"suffix":"”\}],"container-title":"Aerospace Engineering","id":"ITEM-

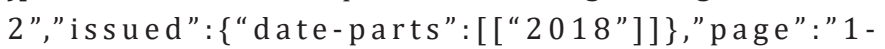
19",'title":"Turbine Engine Lubricant and Additive Degradation Mechanisms","type":" chapter"\},"uris": ["http://www. mendeley.com/documents/?uuid=510df 753-5e81-4c9c96d6-cd7fcb63fe9c"]\},\{“id":"ITEM-3","itemData": \{“author ":[\{“dropping-particle":",,"family":"Mackerer","given":"Carl R","non-dropping-particle":"”,"parse-names":false,"suffix":"”\}, \{“dropping-particle":"',',family":"Barth","'given":"Mary L","nondropping-particle":"”," parse-names":false,"suffix":"”\},\{“drop ping-particle":"',',family":"Krueger","given":"Andrew J","nondropping-particle":"”,"parse-names":false,"suffix":"”\},\{“dro pping-particle":"',',family":"Roy","given":"Timothy A,",nondropping-particle":"',"parse-names":false,"suffix":"”'\}],"contain er-title":"Journal of Toxicology and Environmental Health, Part A",'id":"ITEM-3",'issued":\{“date-parts":[[“1999”]]\},"page":"293328",'title":"Comparison Of Neurotoxic Effects And Potential Risks From Oral Administration Or Ingestion Of Tricresyl Phosphate And Jet Engine Oil Containing Tricresyl Phosphate","type":"articlejournal","volume":"56"\},"uris":["http://www.mendeley.com/ documents $/$ ?uuid=9f825cd9-1c04-477d-879c-4cfe2027f412" ]\}],"mendeley":\{“formattedCitation":"(1-3. The majority of the lubricants utilised in turbine engines are cresyl phosphates, generally termed Tricresyl Phosphate (TCP) at approximately $3 \%$. These cresyl phosphates are Organophosphates (OPs) and are toxic $[3,4]$. Cresyl phosphates contains ortho-, para- and meta- isomers, which can be mono-, di-, or tri- cresyl phosphates as shown in Figure 1. TCP contains 10 congeners as shown in Figure 2. However, there are in addition many other compounds in the cresyl phosphate/TCP commercial formulations. The TCP commercial formulations utilised consist of a complex mixture of cresols, xylenols and phenols, not just the 10 generally referenced TCP isomers shown in Figures 1,2 [3-5]. These are generally referred to as Triaryl Phosphates (TAPs). This then becomes further complicated by the production of pyrolysis breakdown molecules as the oil ages during use $[2,4,6,7]$. Oil utilised in turbine engines is consumed in normal engine operation and a small proportion of this used oil migrates over oil seals used within the engine [8-10]. All current pressurised commercial aircraft, with the exception of the Boing 787, use engine bleed air to ventilate and pressurise the cockpit and the cabin. Because the engine bleed air take-off port is aft of the front engine bearings, fugitive emissions from the engine bearing chamber escapes into the cabin breathing air via the oil seals $[11,12]$. Lower levels of oil can migrate past the seals during transient engine power changes and with changes in air supply configurations as part of normal engine operation. Far less frequently, events such as oil overfill or oil seal failure conditions may occur, leading to higher dose exposure to engine oil fumes. Both scenarios are referred to as 'fume events', with the latter scenarios possibly leading to a visible haze in the cabin. However, there is evidence that there is chronic continual low-dose exposure of aircrew and passengers to fugitive engine emissions during normal flying conditions $[10,13]$. The toxicity of tricresyl phosphate first came to light in the 'Ginger Jake' scandal in the 1920s. Jamaican Ginger was a medicine (also known as Jake). Because of a price increase in castor oil, one of the constituents, the manufacturer substituted it with Tri-Ortho Cresyl Phosphate (TOCP). Consumers of Ginger Jake received very high doses of TOCP. This proved to be neuro-toxic and caused paralysis, part of a syndrome that has subsequently become known as Organophosphate Induced Neuropathy (OPIDN). Subsequent considerations of the toxicity of cresyl phosphates in aircraft cabin air have tended to concentrate solely on the TOCP as the toxic agent and singly on the toxicological endpoint of OPIDN. This approach ignores a large body of science which considers the toxicity of other cresyl phosphate congeners [4,14-20] and toxicological endpoints far more sensitive than OPIDN [21-25]. A critique of this approach in the consideration of aircraft cabin air safety is the motive for writing this paper.

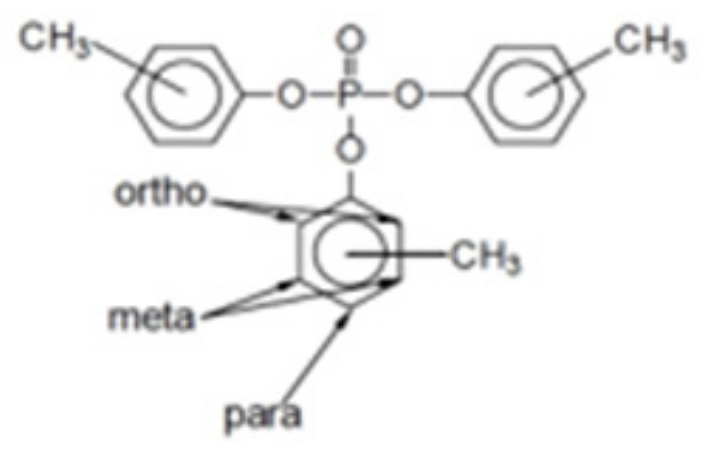

Figure 1: TCP molecule showing designation of $o, m$ and $p$ cresyl groups [4]. 


\section{Comparative toxicology of cresyl phosphates}

If we solely consider the Ortho-Cresyl Phosphate (OCP) isomers, there are Mono- (MOCP), Di- (DOCP) and Tri- (TOCP) ortho-isomers present in jet engine oils. TOCP is said to be at very low levels, however the mono ortho \& di-ortho isomers of cresyl phosphate have been generally ignored in toxicological assessments and are present at higher concentrations.

MOCP is $10 \mathrm{x}$ more toxic than TOCP $[3,17,26,27]$

DOCP is $5 \mathrm{x}$ more toxic than TOCP $[3,17,26,27]$

The technical mixture of the commercial formulation of TCP used in the most widely used engine oil, Mobil Jet Oil II contains [5]:

MOCP 3070ppm in the TCP

DOCP 6ppm in the TCP

TOCP $5 \mathrm{ppb}(0.005 \mathrm{ppm})$ in the TCP

\section{Using Equivalent toxicity}

Ortho TCP content in the oils with TCP at 3\% in oils. The following was published in a 2001conference proceedings in Australia by Winder \& Balouet [28]. Therefore, by solely concentrating on TOCP in deliberating the toxicity of oil in fugitive jet engine fumes, the toxicity of the ortho-isomers in cresyl phosphate is being underestimated by about 6 millionfold, as independently determined by Winder and Balouet. To this the toxicity of the meta and para isomers of cresyl phosphate would need to be added alongside the other (generally unspecified) impurities present in the technical mixture and, additionally, the pyrolysis products which appear as the oil ages in use [29-32].

\section{Risk assessment}

A risk assessment goes through several steps:

Hazard identification: Which requires insight into the system or process under scrutiny.

Hazard assessment: Which can only be performed on hazards that have been considered, requires the application of scientific experimentation (e.g. toxicology) and is therefore costly and time consuming

Exposure assessment: Is required when human exposure to toxic substances is being considered and requires further scientific investigation (e.g. measuring contamination levels). It can be expensive to perform adequately. The route of entry of the toxicant(s) is critical to the exposure assessment.

Risk assessment: Finally, the information collected in steps (1-3) can be combined into a risk assessment. The validity of this final step is totally reliant on the rigour and completeness of the earlier steps. Incorrect conclusions can be caused by not choosing the most sensitive toxicological endpoint, not considering the appropriate route of entry of the toxicant into the body, failure to address the problem of mixtures, etc.

\section{Examples of published risk assessments}

Table 1: Toxicological assessment studies.

\begin{tabular}{|c|c|c|c|c|c|}
\hline Study & $\begin{array}{l}\text { Toxicological } \\
\text { Endpoint }\end{array}$ & $\begin{array}{l}\text { Compounds Consid- } \\
\text { ered }\end{array}$ & $\begin{array}{l}\text { Mixtures Con- } \\
\text { sidered }\end{array}$ & OELs used & Route of Exposure \\
\hline Freudenthal, 1993 [20] & OPIDN & TCP, TOCP & No & No & Oral (hen) \\
\hline Daughtrey, 1996 [29] & OPIDN & ТСР, ТРРТ, ВТР & No & No & Oral (hen) \\
\hline Weiner \& Jortner, 1999* [30] & OPIDN & TAPs, TCP, TOCP & No & No & Oral/dermal \\
\hline Craig \& Barth, 1999 [27] & OPIDN & $\begin{array}{l}\text { TOCP/MOCP/O-iso- } \\
\text { mers }\end{array}$ & No & Yes & Oral/dermal (hen/cat) \\
\hline Mackerer, 1999 [3] & OPIDN & $\begin{array}{l}\text { TCP/ meta/para iso- } \\
\text { mers, OCP /TAPs** }\end{array}$ & No & No & Oral (hen/rat) \\
\hline Daughtrey, 2006 [31] & OPIDN & Oil, TOCP & No & No & Oral (hen) \\
\hline De Ree, $2014^{*}[32]$ & OPIDN & TOCP & No & Yes & Oral (Chicken/cat) \\
\hline CAA, 2004* [33] & OPIDN & TOCP & No & Yes & Oral (chickens) \\
\hline De Boer, 2015* [34] & OPIDN & TCP, TOCP & Yes & Yes & \\
\hline Pleus, $2012 * / 2015^{*} / 2019 *[35-37]$ & OPIDN & TOCP & No & Yes & \\
\hline Wolkoff, 2015* [38] & OPIDN & $\begin{array}{c}\text { TOCP/VOCs/ozone/ } \\
\text { RH }\end{array}$ & Yes & Yes & \\
\hline $\begin{array}{l}\text { Airbus \& UK House of Lords 2000* } \\
\text { [39] }\end{array}$ & OPIDN & TOCP & No & Yes & \\
\hline COT, 2013* [40] & OPIDN & TOCP & No & Yes & \\
\hline Bagshaw, 2015* [41] & OPIDN & TOCР & No & Yes & \\
\hline
\end{tabular}




\section{Open Access Journal of Toxicology}

\begin{tabular}{|c|c|c|c|c|c|}
\hline EASA, 2017 [pyrolysis] [7] & OPIDN & TOCP/oils/various & No & Yes & \\
\hline Costa, $2018^{*}[42]$ & OPIDN/AChE & TCP/TOCP & No & & \\
\hline Schuchardt, $2018^{*}[43]$ & OPIDN & TCP, TOCP, VOCs... & No & Yes & \\
\hline
\end{tabular}

* Risk assessment undertaken based on other studies

${ }^{* *}$ Complex mixtures of methyl phenols (cresols) dimethyl phenols (xylenols), phenol, other alkylated phenols, and small amounts of unidentified impurities.

There is a pattern in following examples of toxicological assessment of the health risks (see (Table 3)) from inhalation of aircraft cabin air. The majority only consider TOCP as the sole toxic substance. They almost all adopt OPIDN as the toxicological endpoint, which is known to require a very high dosage. The research literature concerning OPIDN is all based on ingestion studies and not on inhalational exposure. The publications all consider high dose acute effects only, there is no mention of chronic repeated low dose exposure to cabin fumes. There is no mention of the extensive scientific literature on the mechanisms of low-dose OP exposure toxicity.

Table 2: On a mass basis-cresyl phosphate isomers in the oils.

\begin{tabular}{|c|c|}
\hline Ortho Isomer & ppm in oils \\
\hline TOCP & 0.005 \\
\hline DOCP & 6 \\
\hline MOCP & 3070 \\
\hline TOTAL PPM & 3076 \\
\hline
\end{tabular}

Table 3: Comparative toxicity of ortho-cresyl phosphate isomers.

\begin{tabular}{|c|c|c|c|c|}
\hline \multirow{2}{*}{ Isomer } & \multicolumn{2}{|c|}{ Concentration } & \multicolumn{2}{c|}{ Toxicity } \\
\cline { 2 - 5 } & Absolute $(\mathrm{ppm})$ & Relative to TOCP & Relative to TOCP & $1 \times$ \\
\hline TOCP & 0.005 & 1 & 5 & $6,000 \times$ \\
\hline DOCP & 6 & 1,200 & 6 & $6,140,000 \times$ \\
\hline MOCP & 3070 & $6,14,000$ & 10 & $6,146,001 \times$ \\
\hline
\end{tabular}

Three examples of unsustainable statements resulting from inappropriate risk assessment in the studies

In Table 3. These are representative of the majority of the studies in Table 3. (Example 1) The CAA Report (2004) [33] on page 52 states: "An average man would therefore be able to ingest 7 metric tonnes of pyrolysed oil per day for 74 days without effect." Setting aside the ridiculous nature of this statement, it should be noted that it was made from the following simple linear extrapolation: "Studies of the chronic toxicity of TOCP have shown that the most sensitive species known (chicken) can be fed 20mg. $\mathrm{kg}^{-1}$ (body weight; BW).day-1 without showing signs of OPIDN. Signs of toxicity were observed at $60 \mathrm{mg} \cdot \mathrm{kg}^{-1}(\mathrm{BW})$ day-1. Given the TCP content of the pyrolysed oil supplied to Dstl by QQ Pyestock and used in the previous analysis of oil pyrolysate as $0.19 \mu \mathrm{g} \cdot \mathrm{g}^{-1}$ oil (Table1, Appendix A) Assuming all the TCP has the same toxicity as TOCP (over estimating the toxicity by 100 times). TCP content of oil $0.19 \mu \mathrm{g} \cdot \mathrm{g}^{-1} \equiv 0.19 \mathrm{mg} \cdot \mathrm{kg}^{-1}$ oil $\equiv 0.19 \times 10^{-3} \mathrm{~g} \cdot \mathrm{Kg}^{-1}$ (oil) dosage without OPIDN 20mg. $\mathrm{Kg}^{-1} \cdot \mathrm{day}^{-1} \equiv 20 \times 10^{-3} \mathrm{~g} \cdot \mathrm{Kg}-1$ (BW). day ${ }^{-1}$ Therefore, oral dosage of oil without OPIDN effect is given by $20 \times 10^{-3} \mathrm{~g} \cdot \mathrm{Kg}^{-1}$ (oil).day $1 / 0.19 \times 10^{-3} \mathrm{~g} \cdot \mathrm{Kg}^{-1}(\mathrm{BW}) \cdot \mathrm{day}^{-1}=105 \mathrm{Kg}$ (oil). $\mathrm{Kg}^{-1}(\mathrm{BW}) \cdot$ day $^{-1}$ Assuming a $70 \mathrm{~kg}$ body weight for the average human subject. The total dosage that would not induce OPIDN would be 105x70=7350 Kg.day ${ }^{-1}$. An average man would therefore be able to ingest 7 metric tonnes of pyrolysed oil per day for 74 days without effect." Note that the study was based on an oral dosage study using chickens [34-35]. Exposure to air crew is by inhalation, not ingestion, and therefore this represents a failure of hazard characterisation. All TCPs are assumed to be of the same toxicity as TOCP. This ignores the MOCP and DOCP isomers, which are more toxic and more abundant in jet engine oil, a failure of exposure assessment. The toxicological endpoint assessed is OPIDN, representing a failure of hazard identification. Therefore, this approach fails on all three of the preliminary steps of Risk Assessment.

A further point of interest is that in this CAA Report (2004) is information about the amount of TOCP found on the sooty deposits recovered from ventilation ducts on civil aircraft. In Table 1 of Appendix A of the report it is shown that, on a weight basis, the TOCP content of the deposits is hundreds of times higher than is found in the oil. The majority of particles passing through such ventilation ducts, during the lifetime of the aircraft, will not adhere to the duct walls but pass through into the breathing air in the cabin. The role of OPs adhering to respirable particles in the aetiology of Aerotoxic Syndrome has been discussed by Howard et al., [10]. The main point is that such adsorbed OPs will not be detected if the concentration of OPs in gaseous air is the only thing measured. The CAA report makes no mention or provision in their risk assessment of this further cause of exposure underestimation, despite their inclusion of the evidence of Table 1 in Appendix A. 
Example 2) Dr Pleus [36] presents a risk assessment based on the oral dosage hen studies of Freudenthal [20] in which they administered oils $0.5 \%, 1 \%$, or $3 \%$ TCP (with $0.4 \%$ orthoisomer) by gavage 5 days per week for 10 weeks [20]. Using the toxicological endpoint of OPIDN, he directly extrapolates from an LOAEL in hens of $20 \mathrm{mg} / \mathrm{kg}$ TCP. It should be noted that in the hens in this dosage group there was an over $60 \%$ inhibition of Neuropathy Target Esterase (NTE), indicating very high dosing. This oral dosage LOAEL finding is then subjected to a direct linear scaling to an equivalent human inhalational dose, taking into account body weight, breathing rate etc. Dr Pleus applies none of the usual Uncertainty Factors (UFs) commonly applied in regulatory toxicology (typically 10 for species variability, 10 for human intra-species variability). This simplistic linear transform leads Dr Pleus to calculate and opine that there would need to be 7,000mg of oil per cubic metre of cabin air for there to be any risk of OPIDN in air crew. A grahic is then presented of the Seattle tower with an LOAEL of oil of $7,000 \mathrm{mg} / \mathrm{m}^{3}$ equating to a column of oil reaching the top of the tower, while the oil odour threshold is $<0.45 \mathrm{mg} / \mathrm{m} 3$ and a visible oil haze is assumed to occur at $7 \mathrm{mg} /$ $\mathrm{m}^{3}[35,37]$, leading to much smaller columns of oil in the graphic. This is all a total irrelevance, as OPIDN simply doesn't occur. It is widely taught in undergraduate toxicology courses that ingestion of a toxic substance is almost invariably less harmful than if exposure is by inhalation. There are several reasons for this. The uptake from the alimentary tract is slower than by inhalation. Any toxin that is assimilated across the intestinal wall is taken to the liver by the portal vein. This keeps the initial bolus of toxin away the systemic circulation. The liver is the principal detoxification organ in the body where both Phase 1 and Phase 2 (conjugation) bio-transformations take place [38-43]. This makes the toxic substance more soluble and therefore more likely to be excreted by the kidney. This all leads to a lower sustained concentration of toxin. Not all orally administered toxin is usually assimilated, and some will pass out with the faeces. The following US EPA document summarises this very well [44].

"The only reliable way to characterize inhalation toxicity and to quantify inhalation risk is through the use of inhalation toxicity studies. Chemicals tend to be more toxic by the inhalation route than by the oral route due to rapid absorption and distribution, bypassing of the liver's metabolic protection (portal circulation), and potentially serious portal-of-entry effects, such as irritation, edema, cellular transformation, degeneration, and necrosis. An inhalation risk assessment that is based on oral data generally underestimates the inhalation risk because it cannot account for these factors."

Inhalational toxicology usually makes the, conservative, assumption that $100 \%$ of the inhaled dose is assimilated. Once across the blood/air barrier the toxic substance is in the systemic circulation with direct access to the vital organs without the chance of being detoxified in the liver. This is called the 'First Pass' effect. Therefore, Dr Pleus's approach represents a clear failure of exposure assessment. As with most of the above studies, the assumption of the toxicological endpoint of OPIDN is a failure of hazard characterisation. None of the published evidence on Aerotoxic Syndrome $[10,13,45]$ describes anything like OPIDN and indeed it is safe to say that OPIDN is not seen in air crew. There is a different set of signs and symptoms that are happening at repeated low dose exposures. While OPIDN is associated with changes in cholinesterase levels, the chronic low dose effects in Aerotoxic Syndrome are not [21,25].

Example 3) De Ree [32] take a similar approach. Their $2^{\text {nd }}$ paragraph of Section 4 contains the core of the risk assessment: "Based on the detection limit of ToCP $(0.5 \mathrm{ng} / \mathrm{m} 3)$ maximum uptake via inhalation with a $100 \%$ bioavailability would amount up to $0.02 \mathrm{ng} / \mathrm{kg}$ body weight per day for a crew member of $70 \mathrm{~kg}$ Step 1, Figure 2. This level of exposure was compared with the available lowest No-Observed Adverse Effect Level (NOAEL) of ToCP that was established in chickens and amounts to $1.25 \mathrm{mg} /$ $\mathrm{kg} / \mathrm{d}$ after a repeated daily oral dose for 90 days Craig \& Barth [27]. With respect to toxicological effects of ToCP it should be noted that NOAELs and Lowest Observed Adverse Effect Levels (LOAELs) were determined for two animal species; chicken and cat (reviewed in Craig \& Barth [27]; Johannsen, 1977; Ehrich \& Jortner. For the model, $1 \mathrm{mg} / \mathrm{kg}$ body weight per day was used as a NOAEL. It is recognized that the NOAELs and LOAELs have been obtained from toxicity studies done several decades ago that focused exclusively on major clinical symptoms, such as neuropathology, and not more recently developed neurobehavioral tests. More subtle neurobehavioral changes are usually seen at lower dose levels than those associated with neuropathology. Therefore, an Uncertainty Factor (UF) of 5 was applied to the selected NOAEL. The combined toxicity studies with two non-rodent animal species-chicken and cat-indicate a rather close similarity in NOAELs and LOAELs for ToCP. From a neurotoxicity point of view these two species are also considered to represent the human sensitivity rather well. It is therefore not necessary to add an additional uncertainty factor for comparison with the human situation (UF = 1). This approach is shown in step 2 in Figure 2."

Thus, the regulatory limit they are using to establish safety is based on hen oral exposure toxicology. For 'dose' they assume that TOCP (and nothing else) is present at the LOD (so they maintain that is very conservative because no measurements they made reached LOD) and they assumed $100 \%$ assimilation by inhalation, which is standard toxicology. While the paper does acknowledge the possibility of lower dose, more subtle neurological effects it only assigns an uncertainty factor of 5 to address this. In this paper we see the same adoption of an unrealistic toxicological endpoint, OPIDN, based on ingestion rather than inhalation. The 
paper ignores the complex mixtures problem. The paper avoids citing of the latest science on low dose repeat exposure to OPs. Thus, the use of OPIDN as the toxicological endpoint represents, at best, a failure of hazard assessment and at worst a complete misunderstanding of the clinical picture presenting in aircrew. The failures of risk assessment illustrated in these three examples are repeated in the majority of the other studies listed in Table 3.

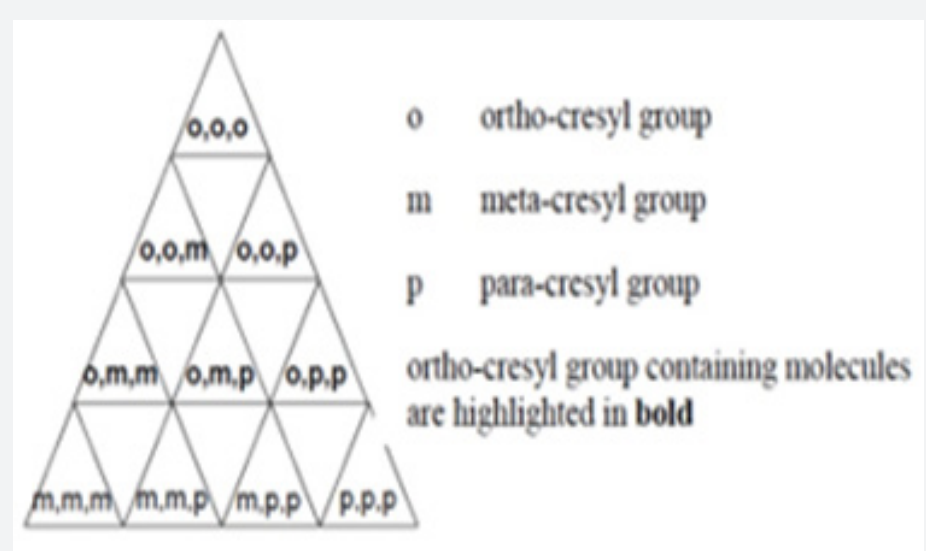

Figure 2: Possible isomers of TCP [4].

\section{Conclusions}

By failing to take into account the increased levels and increased toxicity of the cresyl phosphate ortho isomers other than TOCP, the toxicity of the ortho isomers in TCP are underestimated by a factor of around 6 million. Additionally, toxicity of the non ortho isomers has been ignored, with a sole focus on OPIDN. To this should be added the exposure to OPs that are adherent to the particles in the aerosols in cabin air, which are generally not measured. This latter could be of considerable importance, as previously discussed by Howard [10]. There are widespread reports of illness among aircrew, which have been categorised by Michaelis [13]. The consequences of repeated low dose exposures to OPs have been reviewed by Terry [21]. In that review he states "..... there is now substantial evidence that this canonical (cholinesterase-based) mechanism cannot alone account for the wide variety of adverse consequences of $\mathrm{OP}$ exposure that have been described, especially those associated with repeated exposures to levels that produce no overt signs of acute toxicity. These include covalent binding of OPs to tyrosine and lysine residues, which suggests that numerous proteins can be modified by OPS. In addition, the mechanisms of oxidative stress and neuroinflammation and the known OP targets of motor proteins, neuronal cytoskeleton, axonal transport, neurotrophins and mitochondria. This type of exposure has been associated with prolonged impairments in attention, memory, and other domains of cognition, as well as chronic illnesses where these symptoms are manifested (e.g., Gulf War Illness, Alzheimer's disease)." This is precisely the spectrum of symptoms reported for air crew by Michaelis, Burdon \& Howard [13], who often achieve cumulative career-long flying hours exceeding 20,000 hours. The significance of this pattern of exposure in neurotoxicology has been highlighted by Harris \& Blain [46].

It is widely acknowledged in toxicological science that exposure via inhalation is more toxic, dose for dose, than by ingestion. Inhaled toxicants are assumed to be $100 \%$ assimilated. They pass directly into the systemic circulation, thus avoiding the liver-the major detoxification organ in the body, and having direct access to the brain and heart, possibly assisted by the presence of ultrafine particles [10]. The USEPA advice on this is clear and the failure of the studies in Table 3 to address this represents a major weakness in their use of toxicology in risk assessment. The toxicology of mixtures is more or less completely ignored in the above studies. OPs have been demonstrated to be capable of acting synergistically [47]. In addition chronic pre-exposure to repeated low dose OPs may pre-dispose increased vulnerability to subsequent higher dose OP exposure [48]. This acute-onchronic effect is repeatedly seen in the differential rate of referrals to hospital following fume events on civil aircraft. While a high proportion of aircrew frequently attend hospital after a fume event, passengers do not appear to require this. This is consistent with the published science on the topic. The use of OELs is inappropriate, they are not meant for regulating exposure of the public to toxic substances and they are not appropriate to apply to situations at altitude or for complex mixtures $[10,49,50]$. It is clear that the studies listed in Table 3 are of no relevance in the determination of potential harm to aircrew.

\section{References}

1. Lansdown AR, Lee S (2010) Aviation lubricants. In: Chemistry and Technology of Lubricants: ( $3^{\text {rd }}$ edn). 
2. Johnson D (2018) Turbine Engine Lubricant and Additive Degradation Mechanisms. In: Aerospace Engineering. p. 1-19.

3. Mackerer CR, Barth ML, Krueger AJ, Roy TA (1999) Comparison of Neurotoxic Effects and Potential Risks from Oral Administration or Ingestion of Tricresyl Phosphate and Jet Engine Oil Containing Tricresyl Phosphate. J Toxicol Environ Heal A 57(5): 293-328.

4. Winder C, Balouet JC (2002) The toxicity of commercial jet oils. Environ Res 89(2): 146-164.

5. Mackerer C, Ladov E (2000) Mobil Submission (14a): In: Inquiry into Air Safety-Bae 146 Cabin Air Quality. Canberra: Parliament of The Commonwealth of Australia.

6. Van Netten C, Leung V (2000) Comparison of the constituents of two jet engine lubricating oils and their volatile pyrolytic degradation products. Appl Occup Environ Hyg 15(3): 277-83.

7. EASA Research Project: AVOIL (2015) Characterisation of the toxicity of aviation turbine engine oils after pyrolysis.

8. ExxonMobil (2013) Jet Engine Oil System - Part One. Technical Topics.

9. Edge R, Squires A (1969) Lubricant Evaluation and Systems design For Aircraft Gas Turbine Engines. Warrendale Society of Automotive Engineers 78(3): 1565-1585.

10. Howard C, Johnson DW, Morton J, Michaelis S, Supplee D, et al. (2018) Is a Cumulative Exposure to a Background Aerosol of Nanoparticles Part of the Causal Mechanism of Aerotoxic Syndrome Nanomedicine Nanosci Res. pp. 139.

11. Michaelis S (2016) Implementation of The Requirements for The Provision of Clean Air in Crew and Passenger Compartments Using the Aircraft Bleed Air System. MSc (MSc thesis) Cranfield University.

12. Michaelis S (2018) Aircraft clean air requirements using bleed air systems. Engineering 10: 142-172.

13. Michaelis S, Burdon J, Howard C (2017) Aerotoxic Syndrome: A New Occupational Disease ? Public Heal Panor 3(2): 198-211.

14. Aldridge W (1954) Tricresyl Phosphates and Cholinesterase. Biochem J 56(2): 185-9.

15. Baker PE, Cole TB, Cartwright M, Suzuki SM, Thummel KE, et al. (2013) Identifying safer anti-wear triaryl phosphate additives for jet engine lubricants. Chem Biol Interact 203(1): 257-264.

16. Furlong CE (2011) Exposure to triaryl phosphates: metabolism and biomarkers of exposure. J Biol Phys Che 11(4): 165-171.

17. Siegel J, Rudolph H, Getzkin A, et al. (1965) Effects on Experimental Animals of Long-Term Continuous Inhalation of a Triaryl Phosphate Hydraulic Fluid. Toxicol Appl Pharmacol 7(4): 543-549.

18. European Commission (2009) Regulation (Ec) No 1272/2008 of the European Parliament and Of the Council of 16 December 2008 On Classification, Labelling and Packaging of Substances and Mixtures (CLP).

19. Lipscomb J, Walsh M, et al. (1995) Inhalation toxicity of vapor phase lubricants - AL/OE-TR-1997-0090, USAF Armstrong Laboratory, Occup and Environ Health Directorate, Toxicology Division. Wright-Patterson AFB, Ohio: Wright-Patterson AFB

20. Freudenthal RI, Rausch L, Gerhart JM, Barth ML, Mackerer CR (1993) Subchronic Neurotoxicity of Oil Formulations Containing Either Tricresyl Phosphate or Tri-Orthocresyl Phosphate. Int J Toxicol 12(4): pp. 409-416.

21. Terry AJ (2012) Functional Consequences of Repeated Organophosphate Exposure: Potential Non-Cholinergic Mechanisms.
Pharmacol Ther NIH Public Access 134(3): 355-365.

22. Gao J, Naughton SX, Beck WD, Hernandez CM, Wu G, Wei Z, et al. (2017) NeuroToxicology Chlorpyrifos and chlorpyrifos oxon impair the transport of membrane bound organelles in rat cortical axons. Neurotoxicology 62: 111-123.

23. Gao J, Naughton SX, Wulff H, Singh V, Beck WD, et al. (2016) Diisopropylfluorophosphate Impairs the Transport of MembraneBound Organelles in Rat Cortical Axons. J Pharmacol Exp Ther Mar 356(3): 645- 655 .

24. Hernandez CM, Beck WD, Naughton SX, Poddar I, Adam BL, et al. (2015) Repeated exposure to chlorpyrifos leads to prolonged impairments of axonal transport in the living rodent brain. Neurotoxicology 47:17-26.

25. Naughton SX, Hernandez CM, Beck WD, Poddar I, Yanasak N, et al. (2018) Repeated exposures to diisopropylfluorophosphate result in structural disruptions of myelinated axons and persistent impairments of axonal transport in the brains of rats. Toxicology 406(407): 92-103.

26. Henschler D (1958) Die Trikresylphosphatvergiftung. Experimentelle klärung von problemen der ätiologie und pathogenese (Tricresyl phosphate poisoning. Experimental clarification of problems of etiology and pathogenesis). Klin Wochenscrifte 36(14): 663-674.

27. Craig PH, Barth ML (1999) Evaluation of the hazards of industrial exposure to tricresyl phosphate: a review and interpretation of the literature. J Toxicol Environ Health B Crit Rev 2(4): 281-300.

28. Winder C, Balouet JC (2001) Toxicological and Occupational Hygiene Aspects of Aerotoxic Syndrome. In: Conference of the Australian Institute of occupational hygienists- 19th Annual Conference: The evolving face of occupational hygiene, Novotel, Northbeach, Wollongong, p. 1-5.

29. Pleus R (2015) Expert Report of R Pleus for Air Canada v. Canadian Union of Public Employees -Appeal under subsection 146(1) of the Canada Labour Code of directions issued by a health and safety officer. Occupational Health and Safety Tribunal Canada 14: 08-27

30. Pleus R (2012) Chemicals, Bleed Air, and Health Effects: What the Science Says. In: Aviation Health Conference 2012 2-3 October 2012 London, United Kingdom. Montreal, IATA.

31. Pleus R (2019) Contaminants in Cabin Air. Aviation Health Conference 2019 London, United Kingdom, p. 38.

32. EPA Memorandum (2002) Guidance: Waiver Criteria for MultipleExposure Inhalation Toxicity Studies.United States Environmental protection Agency.

33. Howard C, Michaelis S, Watterson A. The Etiology of 'Aerotoxic Syndrome' - A Toxico- Pathological Viewpoint. Open Acc J Toxicol 1(5): $1-3$.

34. HarrisJ, BlainP (2004) Neurotoxicology: What the neurologist needs to know. J Neurol Neurosurg Psychiatry 75(3): 29-34.

35. Axelrad JC, Howard C V,McLean WG (2002) Interactions between pesticides and components of pesticide formulations in an in vitro neurotoxicity test. Toxicology 173(3): 259-268.

36. AxelradJC, HowardCV, McLeanWG (2003) The effects of acute pesticide exposure on neuroblastoma cells chronically exposed to diazinon. Toxicology 185(1-2): 67-78.

37. ACGIH TLVs and BEIs (2015) Threshold Limit Values for Chemical Substances and Physical Agents. Cincinnati: American Conference of Governmental Industrial Hygienists.

38. Winder C (2006) Hazardous Chemicals on Jet Aircraft: Jet Oils and Aerotoxic Sydrome. Curr Top Toxicol3: 65-88. 
39. House of Lords (2000) UK House of Lords Session 1999-2000 $5^{\text {th }}$ Report HL 121-I Select Committee on Science and Technology - Air Travel and Health. 2000. House of Lords, London.

40. COT (2013) Position Paper on Cabin Air. Committee of Toxicity, London.

41. Bagshaw M (2015) Health Effects of Contaminants in Aircraft Cabin Air. Toxicol Sci p. 42.

42. Costa LG (2018) Organophosphorus Compounds at 80: Some Old and New Issues. Toxicol Sci.

43. Schuchardt S, Koch W, RosenbergerW (2019) Cabin air qualityQuantitative comparison of volatile air contaminants at different flight phases during 177 commercial flights. Build Environ 148: 498-507.

44. Wolkoff P, Crump DR, Harrison PTC (2016) Pollutant exposures and health symptoms in aircrew and office workers: Is there a link? Environ Int 87: 74-84.
45. Daughtrey W, Biles R, Jortner B, Ehrich M (1996) Subchronic delayed neurotoxicity evaluation of jet engine lubricants containing phosphorus additives. Fundam Appl Toxicol 32(2): 244-249.

46. Weiner M, Jortner B (1999) Organophosphate -Induced Delayed Neurotoxicity of Triaryl phosphates. Neurotoxicology 20(4): 653-674.

47. Daughtrey W, Biles R, Jortner B, Ehrich M (2006) Delayed neurotoxicity in chickens: 90-day study with Mobil jet oil 254 - Abstract 1467. In: SOT 2006 ANNUAL MEETING.

48. de Ree H, Van den Berg M, Brand T, Mulder Dj et al. ( 2014) Health Risk Assessment of Exposure to TriCresyl Phosphates (TCPs) In Aircraft: A Commentary. Neurotoxicology 45: 209-215.

49. CAA (2004) CAA PAPER 2004/04. Cabin Air Quality. Gatwick: CAA.

50. de Boer J, Antelo A, Van der Veen, I (2015) Tricresyl phosphate And the Aerotoxic Syndrome of Flight Crew Members - Current Gaps In knowledge. Chemosphere 119: S58-S61.

\section{Your next submission with Juniper Publishers} will reach you the below assets

- Quality Editorial service

- Swift Peer Review

- Reprints availability

- E-prints Service

- Manuscript Podcast for convenient understanding

- Global attainment for your research

- Manuscript accessibility in different formats ( Pdf, E-pub, Full Text, Audio)

- Unceasing customer service

Track the below URL for one-step submission https://juniperpublishers.com/online-submission.php 